\section{Passado e presente da sociologia norte-americana}

Stephen Turner. American sociology: from pre-disciplinary to post-normal. Londres, Palgrave, 2014. 137 páginas.

\section{Carlos Benedito Martins}

A constituição e o desenvolvimento da sociologia norte-americana vêm merecendo uma contínua reflexão por parte de seus praticantes. Em 1990, Stephen Turner e Jonathan Turner publicaram o influente livro The impossible science: an institutional analysis of American sociology. Em um período mais recente, a trajetória histórica, social e universitária da sociologia norte-americana foi objeto de uma ampla análise explorada na coletânea Sociology in America, organizada por Craig Calhoun, que contou com a participação de renomados acadêmicos, entre eles Stephen Turner, Patricia Collins, Charles Camic, Barbara Laslett, Andrew Abbot e Immanuel Wallerstein (Turner e Turner, 1990; Calhoun, 2007).

O livro American sociology: from pre-disciplinary to post-normal, de Stephen Turner - que tem realizado importantes contribuiçóes acadêmicas na área de teoria social -, insere-se nessa trilha. Traça um instigante percurso da sociologia norte-americana desde seu início, no século XIX, até a época presente e sua relação com diferentes movimentos sociais existentes nesse período. Em sua perspectiva durante a fase pré-disciplinar, que cobre o final do século XIX e as primeiras décadas do século posterior, a sociologia norte-americana esteve, em grande medida, associada ao movimento de reforma social. Para o autor, no período atual, a proposta de uma sociologia pública levada a cabo por Michael Burawoy tem impulsionado também a sociologia norte-americana a estabelecer uma relaçáo orgânica com certos tipos de movimentos sociais daquela sociedade. Na percepção de Turner, no entanto, o envolvimento da sociologia com as diferentes configuraçóes de movimentos sociais tanto no seu período inicial como no presente pouco contribuiu para sua consolidação científica (Blau e Smith, 2006; Deegan, 1988).

A leitura do livro assinala que o início da sociologia norte-americana no século XIX e nos anos iniciais do século seguinte foi marcado por uma profunda preocupação com as ideias de reforma e de progresso social. Esse ideário mobilizava um vasto conjunto de instituiçóes, como igrejas, organizaçôes filantrópicas, governos estaduais etc. Em vários centros urbanos existiam charity organization societies (sociedades de organizaçóes de caridade), que prestavam serviços para as camadas pobres dos centros urbanos, coletavam informaçóes sobre sua situação e ao mesmo tempo procuravam formular explicaçóes sobre as causas da pobreza. A organização de reforma social mais poderosa nesse período, Woman's Christian Temperance Union, fundada em 1874, se opunha à utilização de crianças no mercado de trabalho, pleiteava a proteção da mulher nos ambientes de domicílio e de trabalho, apoiava o voto feminino etc.

Ainda em relação aos movimentos de reforma social, os atores que os integravam, como advogados, educadores e filantropos, passaram a reivindicar uma presença no meio universitário. Dessa forma, em 1880, criaram a American Social Science Association, que também foi frequentada temporariamente por uma nova geração de cientistas sociais. Essa organização buscou imprimir uma abordagem mais objetiva aos diversos problemas sociais, patrocinando a realizaçáo de vários estudos e pesquisas (surveys) apoiados por organizações filantrópicas e por fundações, tal como a Russell Sage Foundation. Esses diversos surveys realizados sobre as condiçóes sociais de vida urbana, impulsionados pelo movimento reformista - dentre os quais se destacam The Pittsburgh Survey, realizado entre 1909 e 1914, e Springfield Survey, desenvolvido entre 1918 e 1920 -, contribuíram para despertar a atenção de uma nova geração de sociólogos sobre a existência desse rico material empírico (Calhoun, 2007, p. 1-38; Faris, 1967).

De seu lado, o meio universitário beneficiou a emergente sociologia norte-americana, em razão da reestruturação do sistema de ensino superior daquele país, iniciado no final do século XIX e fortemente influenciado pelo modelo de universidade concebido por Humbolt para as instituiçôes alemãs, no qual a pesquisa era concebida como atividade fundamental. O surgimento de universidades 
de pesquisas nesse período foi impulsionado pela crença da elite política e empresarial de que a produção de conhecimentos poderia oferecer soluções para os múltiplos problemas sociais que surgiram no bojo de um acelerado processo de industrialização e urbanização (Reuben, 1995).

A sociologia beneficiou-se também da atuação de fundaçóes privadas de pesquisa. Determinadas universidades norte-americanas contaram com expressivos aportes financeiros da Carnegie Corporation, da Rockefeller Foundation, por meio da Laura Spelman Rockefeller Foundation, que criou, em 1923, o Social Science Research Council. Os subsídios da Rockefeller Foundation não visavam promover a criação de uma "ciência social pura", mas apoiar o desenvolvimento de uma sociologia que, por meio de dados empíricos, pudesse contribuir para a solução de questóes sociais relevantes. A esse propósito, seria oportuno assinalar que um dos primeiros departamentos de sociologia no contexto norte-americano foi criado na Universidade de Chicago com um substancial apoio financeiro de John Rockefeller para a sua fundação, em 1892, tendo o departamento desenvolvido uma agenda de pesquisa sobre problemas urbanos (Bulmer, 1984; Geiger, 1986).

$\mathrm{Na}$ fase inicial de implementação dos departamentos de sociologia, não era incomum a contratação de líderes reformistas e/ou de indivíduos que desenvolviam trabalhos em organizaçóes assistenciais como seus docentes. Vários presidentes de universidades renomadas, assim como destacados professores que atuavam nas ciências sociais, mantinham estreitos laços com organizaçóes inseridas no movimento reformista. O presidente da Universidade Johns Hopkins, por exemplo, Daniel Gilman, participava do movimento cooperativista e mantinha relaçóes com as Charity Organization Societies. Envolveu alunos e professores com esse movimento de organizaçóes filantrópicas ao mesmo tempo em que pleiteava a inclusão de uma disciplina denominada por ele de "caridade científica" no interior da universidade. Em Chicago, a figura de Jane Addams destacava-se como uma liderança central no movimento reformista. A Hull House, originalmente sediada em um barracão reformado e inaugurado por ela em 1889 para oferecer serviços assistenciais para as camadas pobres, expandiu-se para outros prédios nos anos seguintes e transformou-se não apenas em um centro de oferta gratuita de serviços sociais, mas também em um espaço no qual reformadores, políticos e acadêmicos se encontravam com frequência para discutir questóes sociais (Recchiuti, 2007). Albion Smal, que chefiou por quase trinta anos o departamento de sociologia da Universidade de Chicago e que acreditava que a sociologia poderia oferecer uma importante contribuição para a reforma social, era um dos frequentadores habituais da Hull House. Em sua companhia, George Herbert Mead e Charles Henderson, que eram também professores de ciências sociais da Universidade de Chicago. O sociólogo William Thomas, também da Universidade de Chicago, marcava presença na Hull House, o que lhe permitiu obter um considerável volume de informações empíricas (Janowitz, 1966; Volkart, 1951).

Entretanto, na avaliação do autor, entre os anos 1920 e 1930 ocorreu um relativo afastamento da sociologia do movimento reformista, sendo um motivo o desenvolvimento por parte da disciplina de abordagens metodológicas diversificadas, que favoreceram seu amadurecimento científico, como se vê nos exemplos a seguir. Franklin Giddings, por exemplo, no longo período em que esteve na direção do departamento de sociologia de Columbia, entre 1890 e 1920, influenciado pelas concepçóes de ciência de Karl Pearson, trabalhou ativamente para incorporar métodos estatísticos nas investigaçôes sociológicas (Camic, 1996). Na mesma direção, o departamento de sociologia de Chicago forneceu uma base empírica, desenvolvendo técnicas qualitativas, como observação participante, história de vida etc. O trabalho de Robert Lynd e Helen Lynd, Middletown: a study of American culture, publicado em 1929, combinou observações etnográficas com dados estatísticos. $\mathrm{O}$ pioneiro trabalho The polish peasant in Europe and America, publicado por William I. Thomas e Florian Znaniecki, entre 1918 e 1920, integrou de forma exitosa um exaustivo material empírico com uma reflexão teórica, iniciando uma nova etapa na trajetória da sociologia norte-americana (Fine, 1995). Por meio dessas diversas contribuiçôes metodológicas, a sociologia foi se afastando, gradativamente, dos pontos de vista reformistas, buscando infundir um grau de maior objetividade em suas análises (Smith, 1994). 
Um marco nesse processo de amadurecimento científico da disciplina, na visão do autor, foi a criação da American Sociological Society (ASS), em 1930, uma vez que a associação procurou imprimir uma identidade científica e profissional a seus membros. Os sociólogos começaram a priorizar suas atividades acadêmicas, relegando a segundo plano sua participação em movimentos reformistas. Procurando afirmar um modelo de trabalho acadêmico, a ASS passou a vetar a entrada de praticantes amadores e de membros do movimento de reforma que não possuíssem vínculos acadêmicos. Poucos anos depois, criou-se a Sociological Research Association, que adotou o critério de autorrecrutamento de seus membros e que passou a ser frequentada pela elite da sociologia norte-americana. $\mathrm{Na}$ dinâmica desse processo de institucionalizaçáo da sociologia, ocorreu em 1936 a criaçấo da American Sociological Review, que, ao lado do American Journal of Sociology, criado em 1895, passou a funcionar como uma instância de legitimação acadêmica dos artigos publicados pelos sociólogos norte-americanos (Bannister, 1987; Lengermann, 1979).

No pós-guerra, a balança de poder acadêmico deslocou o departamento de Chicago a favor dos departamentos de sociologia de Harvard e de Columbia. Sobre o caso da Universidade de Harvard, assinala o autor que, nos anos de 1930, o futuramente célebre sociólogo funcionalista Talcott Parsons era ainda uma figura marginal e um autor de pequeno impacto na disciplina. Durante a guerra recebeu fundos da Carnegie Corporation para desenvolver um ambicioso projeto teórico. Seu trabalho The structure of social action, publicado em 1937, recorreu exclusivamente a pensadores europeus para formar um quadro analítico que propositadamente ignorou o que vinha sendo realizado na sociologia norte-americana. Enquanto Parsons desenvolvia uma abrangente teoria voltada para a compreensáo da açáo humana, Robert Merton cujas fontes de inspiração também eram europeias - propunha no departamento de sociologia de Columbia uma teoria de médio alcance, procurando integrar teoria e pesquisa empírica. Também na Universidade de Columbia, Paul Lazarsfeld, que, como nos informa o autor, não possuía formaçáo em sociologia e não tinha interesse na disciplina, instalou o Bureau of Applied Social Research, vinculado ao departamento de sociologia daquela universidade (Camic, 1996).

$\mathrm{Na}$ apreciaçáo do autor, a proeminência dos departamentos de sociologia de Harvard e Columbia, entre as décadas de 1940 e 1960, produziu um falso clichê, segundo o qual a sociologia norte-americana seria uma combinaçáo entre o funcionalismo conduzido por Parsons e Merton e as pesquisas de survey capitaneadas por Lazarsfeld. Ao contrário, ressalta que existia uma pluralidade de orientaçóes teóricas no período. Assim, a presença de Max Weber inspirou trabalhos sobre poder, civilidade e intelectuais, conduzidos por Edward Shils em Chicago, e instigou os escritos sobre estrutura social e caráter liderados por Hans Gerth e Wrigth Mills. As pesquisas realizadas por Anselm Strauss, Harold Garfinkel, Aaron Cicourel, Erving Goffman e outros, influenciadas direta ou indiretamente pelo interacionismo simbólico, distanciavam-se do eixo Harvard-Columbia (Gouldner, 1970). A sociologia realizada em determinadas universidades estatais era indiferente ao funcionalismo e concentrava seus esforços em analisar problemas locais. Dessa forma, durante as décadas de 1940 a 1960, a sociologia norte-americana teve grande produtividade intelectual, sendo orientada pelo ideal de realizaçáo de um trabalho científico que não se reduziu ao monopólio de uma postura positivista, uma vez que foi fomentada por uma diversidade teórica e metodológica.

Ao analisar a situação da sociologia norte-americana nos anos de 1970, Turner ressalta que uma crise de grandes proporçôes abateu-se sobre a disciplina: franca hostilidade das novas geraçōes à orientaçáo funcionalista, que contribuiu para o descrédito dessa vertente; sensível decréscimo das fontes de financiamento para as atividades da disciplina; declínio das matrículas nos cursos de sociologia na graduaçáo, no mestrado e doutorado, que levou ao fechamento do departamento de sociologia da Universidade de Washington; dificuldades de inserçáo de titulados no mercado de trabalho, o que possivelmente conduziu jovens que aspiravam tornar-se sociólogos a realizar cursos oferecidos nas business school. O ideal de imprimir um padrão científico ao trabalho sociológico, que marcou as 
décadas anteriores, enfraqueceu-se enquanto ponto de referência. Ao contrário, o trabalho sociológico foi substituído pela prática da expertise, ou seja, a utilização de métodos quantitativos na explicação de determinados fenômenos, vinculados a interesse públicos e/ou privados. $\mathrm{Na}$ avaliaçáo do autor, vários trabalhos sobre educaçáo realizados por James Coleman - que fora estudante de Merton e Lazarsfeld - expressam essa vertente de expertise, afastando-se de um ideário de afirmação científica da disciplina (Coleman, 1966).

O colapso da demanda de estudantes de sociologia entre os anos de 1970 e 1980 teve um efeito diferente entre os departamentos. Os que estavam inseridos na Ivy League e outros, em termos de reconhecimento acadêmico, ficaram relativamente imunes à escassez de alunos de graduação. Alguns deles chegaram a perder a totalidade desses alunos e sobreviveram apenas com programas de doutorado. No entanto, os departamentos que não pertenciam às instituiçôes de elite promoveram ajustes. Por um lado, intensificaram a oferta de cursos optativos da disciplina na graduaçáo para outras áreas do conhecimento - com isso, os docentes centralizaram suas atividades acadêmicas nos afazeres do ensino de sociologia. Por outro lado, os cursos de graduação atenuaram a presença e/ou a quantidade de determinadas disciplinas consideradas impopulares pelos alunos, como estatística. Procuraram incluir também determinados tópicos que pudessem atrair alunos de graduação de sociologia para suas instituiçóes. Com isso, criou-se uma divisão do trabalho acadêmico entre os departamentos: os que desfrutavam de posiçôes dominantes focaram na pesquisa e os que se distanciavam dos círculos dominantes concentraram-se nas atividades de ensino.

A geração que se opôs à orientação funcionalista, gradativamente, ocupou espaço na American Sociological Association (ASA), que era praticamente controlada pelos quadros dos departamentos de sociologia mais reputados. Esse grupo dominante buscou acomodar a demanda de participação de sociólogos alocados em instituiçôes universitárias de menos reconhecimento acadêmico, facultando-lhes o acesso à programação anual da ASA, por meio da modalidade de "sessóes", que no decorrer do tempo proliferaram de forma expressiva. Por volta dos anos 1990, determinados cargos da ASA foram ocupados por sociólogos que não trabalhavam nos departamentos de elite da sociologia, o que foi descrito como "diluiçẫo da elite" (Simpson e Simpson, 2001). O autor salienta que os departamentos de elite estavam estrategicamente abrindo mão de parte do seu controle da ASA para preservar o domínio completo das revistas American Journal of Sociology e American Review of Sociology, que, em sua visão, tornaram-se um cartel de periódicos inserido no funcionamento de outro cartel, comandado por cinco departamentos da disciplina, que eram os de Harvard, Chicago, Columbia, Wisconsin e Berkeley. A alta taxa de rejeiçáo desses dois periódicos, e de outros próximos da elite sociológica, contribuiu para a criação de revistas específicas tais como Rural Sociological Society, Society for the Study of Simbolic Interaction, Society for the Study of Social Problems etc. Esse processo atendeu também à diversificação dos grupos de pesquisa.

Na parte final do livro, o autor aborda determinadas mudanças ocorridas na universidade norte-americana contemporânea, tais como a introdução de políticas de açáo afirmativa e a expressiva participação de mulheres nas matrículas. Nos cursos de sociologia, as mulheres superaram a presença dos homens na graduação, no mestrado e doutorado. Em alguns departamentos, especialmente na Costa Oeste, os estudantes participaram da contratação de docentes, utilizando critérios políticos no processo. Em outros departamentos, adotaram-se critérios de ação afirmativa na admissão de docentes. O movimento de mulheres e a assertividade das reivindicaçōes postuladas pelos sociólogos negros foram recebidos favoravelmente por vários segmentos da academia como importante contribuição para modificar o caráter discriminador da universidade.

$\mathrm{Na}$ perspectiva do autor, essas mudanças repercutiram na forma de considerar o trabalho sociológico, na medida em que determinados grupos imprimiram um comportamento de ativismo e de engajamento social, relegando a um segundo plano o compromisso com um ideário científico. A disposição de aliar a sociologia a uma militância adotada por alguns grupos, de certa forma, relembra a relação da sociologia em sua fase pré-disciplinar com movimentos de reforma social no século XIX, abor- 
dado na parte inicial do seu livro. Com isso, a etapa presente da sociologia aproxima-se dos argumentos favoráveis a essa conexão apresentados por Robert Lynd, na década de 1930 (Lynd, 1939)

As demandas iniciais de inclusão dos black studies nas universidades norte-americanas postulavam que os sociólogos negros deveriam náo apenas ministrar a nova disciplina como deter o controle do currículo, a fim de que este refletisse o seu ponto de vista. Essas demandas foram parcialmente aceitas e pouco a pouco a disciplina black studies foi introduzidas nos cursos acadêmicos. Os sociólogos negros envolvidos com a demanda dessa disciplina criaram a Caucus of Black Sociologist, que posteriormente transformou-se na Association of Black Sociologist. Passaram a reivindicar participação nos comitês da American Sociological Association, pleitearam atuar como referees na análise de artigos do American Journal of Sociology e exigiram estar sempre representados como expositores e debatedores de papers nos programas desta associação que abordassem questōes de relevância para a comunidade negra (Conyers, 1992).

O livro destaca que a geração de mulheres que exerceu a profissão na década de 1950 encontrou obstáculos explícitos, em função de estereótipos nutridos por sociólogos que ocupavam posiçôes de mando na disciplina: parte deles acreditava que as mulheres abandonariam seus projetos profissionais em funçáo do casamento (Laslett, 2007). A principal organização das mulheres na sociologia norte-americana, a Sociologist for Women Society (SWS), começou a se organizar para romper as barreiras que enfrentavam para ter acesso à disciplina. A SWS realizou um trabalho contra formas de discriminação profissional das mulheres, lutou pela sua participação na sociologia e passou a publicar o influente periódico Gender and Society. As açōes afirmativas e o trabalho do grupo SWS mudaram a composição de gênero dos docentes nos departamentos de sociologia, na medida em que as mulheres tiveram acesso a eles. $\mathrm{O}$ mesmo processo ocorreu com a American Sociological Association, onde as mulheres passaram a se candidatar para todas as posiçōes: algumas delas, em início de carreira e provenientes de departamentos menos prestigiosos, obtiveram cargos, ganhando de sociólogos seniores oriundos de departamentos prestigiosos. Desde o fim do milênio passado, as mulheres passaram a ser eleitas para a presidência da ASA. Nesse contexto de mobilização, o autor salienta que na época presente ocorreu a reabilitação e canonizaçáo de Jane Adda$\mathrm{ms}$ - figura de destaque no movimento reformista do início do século passado - por parte de algumas feministas, reivindicado sua inclusão como uma das fundadoras da sociologia norte-americana (Deegan, 1988). A posiçāoo de Stephen Turner a respeito desse movimento de recuperação é clara: Jane Addams não possuía nenhuma preocupação com a sociologia, não tinha qualquer ambição de torná-la uma disciplina científica. Seu trabalho e seu interesse estavam voltados exclusivamente para a reforma social.

Ao assinalar a mescla entre ideologia e sociologia presente no trabalho de determinados grupos no contexto da sociologia norte-americana, o autor recorre a uma passagem do livro de Louis Horowitz, The decomposition of sociology, amplamente utilizado por ele em sua argumentação para demarcar a separação entre problema sociológico e problema social, ciência e ideologia. Nessa passagem do livro de Horowitz, este, por sua vez, cita um artigo de 1984, publicado na Mid-American Review of Sociology, de autoria do sociólogo Michael Hill, companheiro de Mary Jo Deegan, artigo em que Hill pleiteia a incorporaçáo de ideologia enquanto elemento de legitimação de grupos militantes que utilizam a sociologia, afirmando: "primeiro ideologia, segundo axiologia e terceiro epistemologia".

Turner salienta que o movimento das mulheres recorreu às reflexóes de Thomaz Khun sobre o funcionamento do conhecimento científico e pleiteou a fundação de um novo paradigma para suas formulaçóes explicativas: o paradigma de gênero. No entanto, discordando dessa reivindicação, Turner sugere que, quando um grupo de sociólogos postula para si o estabelecimento de um novo paradigma, os seus pressupostos são assumidos como um conjunto de convicçôes, ou seja, como uma doxa pelos seus seguidores. Do mesmo modo, o autor considera que a proposta de Michael Burawoy de levar a cabo uma sociologia pública, capaz de aproximar os sociólogos dos diversos movimentos sociais - o que para Turner mereceu poucas críticas na sociologia norte-americana -, os têm convertido em intelectuais or- 
gânicos desses movimentos, na esteira da formulação proposta por Gramsci (apud Horowitz, 1993).

Ao longo do texto constata-se que os departamentos de sociologia norte-americana de maior prestígio acadêmico possuem uma cultura que privilegia a pesquisa, enfatiza um padrão de trabalho científico e são defensores desse ethos acadêmico (Max, 1990). No entanto, o autor destaca que uma parte expressiva da sociologia norte-americana, nos dias atuais, lamentavelmente, considera irrelevante o legado teórico e metodológico edificado - a partir de diversas orientaçóes - pelas geraçóes de sociólogos que trabalharam entre os anos de 1940 e 1970, visando fornecer um alicerce científico para a sociologia. $\mathrm{O}$ panorama atual da sociologia norte-americana construído pelo autor tende a indicar que a disciplina vem sendo produzida por um emaranhado de grupos, cada qual orientando-se a partir de suas agendas políticas específicas, ora reivindicando um "paradigma" particular para si, ora instrumentalizando a atividade teórica, tornando a defesa de determinadas causas sociais a motivação primordial da produção do conhecimento.

A leitura do livro sugere que a disposição de produzir um conhecimento sociológico em defesa dos interesses de determinados movimentos sociais corre o risco de conduzir o investigador a estabelecer uma relação incontrolada com seu objeto de análise. Isso tende a confundir a explicação sociológica de um determinado movimento social com o ponto de vista dos atores que neles participam. Com essa adesão às crenças dos participantes dos movimentos sociais, o investigador abdica da realização de um trabalho sociológico objetivo, minando a credibilidade da própria disciplina. Diante desse cenário, o autor indaga: na medida em que a sociologia norte-americana vem se pautando, de forma crescente, por agendas políticas construídas por diferentes grupos, a disciplina tem condiçóes de sobreviver nos espaços científico e universitário?

American sociology: from the pre-disciplinary to post-normal é um agradável convite ao leitor interessado em refletir sobre os condicionantes institucionais e sociais que têm permeado o desenvolvimento e os rumos da sociologia norte-americana. Trata-se ainda de um livro que fornece valiosas informações sobre as mudanças na configuração aca- dêmica e geracional da universidade daquele país, abordando a existência de uma divisão hierárquica entre seus distintos departamentos de sociologia e o impacto desses fenômenos na vida institucional da disciplina praticada nesse contexto societário. Ao analisar os ganhos e perdas da vinculação da sociologia com movimentos sociais tanto do passado como do presente, Stephen Turner realiza uma contundente separação entre o compromisso do investigador de fornecer uma análise objetiva dos fatos e a explicaçáo sinuosa embasada por crenças ideológicas. Certamente, esse denso e corajoso livro produzirá acalentadas polêmicas, mas, seguramente, fornece uma profícua reflexão não apenas sobre os rumos da sociologia norte-americana, mas também para (re)pensar os caminhos de outras sociologias nacionais.

\section{BIBLIOGRAFIA}

BANNISTER, R. (1987), Sociology and scientism: the American quest for objectivity 1880-1940. Chapell Hill, The University of North Caroline Press.

BULMER, M. (1984), The Chicago School of sociology: institutionalization, diversity, and the rise of sociology research. Chicago, The University of Chicago Press.

BLAU, J. \& SMITH, K. (2006), Public sociologies reader. Oxford, Rowman \& Littlefield Publishers.

CALHOUN, C. (org.). (2007), Sociology in America: a history. Chicago, The University of Chicago Press.

CAMIC, C. (1996), “Three departments in search of a discipline: localism and interdisciplinary interaction in American sociology, 18901940". Social Research, 62 (4): 1003-1033.

COLEMAN, J. ([1966] 1996), Equality of educational opportunity. Comissionado pelo US Department of Health, Education, and Welfare. Washington, Office of Education.

CONYERS, J. (1992), "The Association of Black Sociologist: a descriptive account from an 'insider". The American Sociologist, 23: 49-55.

DEEGAN, M. J. (1988), Jane Addams and the men 
of the Chicago School. New Brunswick, Transaction Books.

FARIS, R. (1967), Chicago sociology (1920-1932). Chicago, The University of Chicago Press.

FINE, G. (1995), "A second Chicago School? The development of a postwar American sociology", in Gary Fine (org.), A second Chicago School? The development of a postwar American sociology, Chicago, The University of Chicago Press.

GEIGER, R. (1986), To advance knowledge: the growth of American research universities (19001940). Nova York, Oxford University Press.

GOULDNER, A. W. (1970), The coming crisis of western sociology. Nova York, Basic Books.

JANOWITZ, M. (org.). (1966), W. I. Thomas on social organization and personality: select papers. Chicago, The University of Chicago Press.

HOROWITZ, L. (1993), The decomposition of the sociology. Oxford, Oxford University Press.

LENGERMANN, P. M. (1979), "The founding of the Sociological Review: the anatomy of a rebellion". American Sociological Review, 44 (2): 185-198.

LASLETT, B. (2007), "Feminist sociology in the twentieth-century United States; live history in historical context", in Craig Calhoun (org.), Sociology in America: a history, Chicago, The University of Chicago Press.

LYND, R. (1939), Knowledge for what? The place of social science in American culture. Princeton, Princeton University Press.

MAX, G. (1990), "Reflections on academic success and failure: making it, reshaping it", in Reinhard Bendix e Bennet Berger (eds.), Authors of their own lives, Berkeley, University of California Press.

RECCHIUTI, J. L. (2007), Civic engagement social science and progressive-era reform in New York City. Filadélfia, University of Pennsylvania Press.

REUBEN, J. (1995), The shaping of the modern university. Chicago, The University of Chicago Press.

SIMPSON, I. H. \& SIMPSON, R. (2001), "The transformation of the American Sociological Association", in Stephen Cole (org.), What's wrong with sociology?, New Brunswick, Transaction Publishers.

SMITH, M. (1994), Social science in the crucible: the American debate over objective and purpose. Durham, Duke University Press.

TURNER, S. \& TURNER, J. (1990), The impossible science: an institutional analysis of American sociology. Londres, Sage.

VOLKART, E. (1951), Social behavior and personality: contributions of $W$. I. Thomas to theory and social research. Nova York, Social Science Research Council.

CARLOS BENEDITO MARTINS é professor titular do Departamento de Sociologia da Universidade de Brasília. Foi professor visitante da Universidade de Columbia em 2006 e da Universidade de Oxford em 2012. E-mail: carlosb@unb.br.

DOI: http//dx.doi.org/10.17666/3087163-169/2015 